\title{
Times to Discontinue Antidepressants Over 6 Months in Patients with Major Depressive Disorder
}

\author{
Woo-Young Jung ${ }^{1}$, Sae-Heon Jang ${ }^{2}$, Sung-Gon Kim ${ }^{1,3} \bowtie$, Young-Myo Jae ${ }^{2}$, Bo-Geum Kong ${ }^{4}$, \\ Ho-Chan $\mathrm{Kim}^{5}$, Byeong-Moo $\mathrm{Choe}^{6}$, Jeong-Gee Kim${ }^{7}$, and Choong-Rak Kim ${ }^{8}$ \\ ${ }^{1}$ Department of Psychiatry, Pusan National University Yangsan Hospital, Yangsan, Republic of Korea \\ ${ }^{2}$ Department of Psychiatry, Bongseng Memorial Hospital, Busan, Republic of Korea \\ ${ }^{3}$ Department of Psychiatry, Pusan National University College of Medicine, Busan, Republic of Korea \\ ${ }^{4}$ Department of Psychiatry, Inje University Paik Hospital, Busan, Republic of Korea \\ ${ }^{5}$ Department of Psychiatry, Kosin University Gospel Hospital, Busan, Republic of Korea \\ ${ }^{6}$ Department of Psychiatry, Dong-A University Medical Center, Busan, Republic of Korea \\ ${ }^{7}$ Department of Psychiatry, Maryknoll Medical Center, Busan, Republic of Korea \\ ${ }^{8}$ Department of Statistics, Pusan National University, Busan, Republic of Korea
}

Objective The aim of the present study was to investigate differences in discontinuation time among antidepressants and total antidepressant discontinuation rate of patients with depression over a 6 month period in a naturalistic treatment setting.

Methods We reviewed the medical records of 900 patients with major depressive disorder who were initially prescribed only one kind of antidepressant. The prescribed antidepressants and the reasons for discontinuation were surveyed at baseline and every 4 weeks during the 24 week study. We investigated the discontinuation rate and the mean time to discontinuation among six antidepressants groups.

Results Mean and median overall discontinuation times were 13.8 and 12 weeks, respectively. Sertraline and escitalopram had longer discontinuation times than that of fluoxetine, and patients who used sertraline discontinued use significantly later than those taking mirtazapine. No differences in discontinuation rate were observed after 24 weeks among these antidepressants. About $73 \%$ of patients discontinued antidepressant treatment after 24 weeks.

Conclusion Sertraline and escitalopram tended to have longer mean times to discontinuation, although no difference in discontinuation rate was detected between antidepressants after 24 weeks. About three-quarters of patients discontinued antidepressant maintenance therapy after 24 weeks.

Psychiatry Investig 2016;13(4):440-446

Key Words Antidepressant, Discontinuation, Escitalopram, Major depressive disorder, Sertraline.

\section{INTRODUCTION}

Major depressive disorder (MDD) is a common, very disabling, and costly psychiatric disorder. The 12 -month and lifetime prevalence rates of MDD are $6.6 \%$ and $16.2 \%$, respectively.1,2 Patients with MDD function more poorly than other primary care outpatients in physical activities, occupational or role responsibilities, and social activities. ${ }^{3} \mathrm{~A}$ recent

Received: May 6, 2015 Revised: September 12, 2015

Accepted: October 24, 2015 Available online: March 23, 2016

$\triangle$ Correspondence: Sung-Gon Kim, MD, PhD

Department of Psychiatry, Pusan National University College of Medicine, 20 Geumo-ro, Meulgeum-eup, Yangsan 50612, Republic of Korea

Tel: +82-55-360-2461, Fax: +82-51-366-7224, E-mail: sungkim@pusan.ac.kr

(a) This is an Open Access article distributed under the terms of the Creative Commons Attribution Non-Commercial License (http://creativecommons.org/licenses/by$\mathrm{nc} / 3.0$ ) which permits unrestricted non-commercial use, distribution, and reproduction in any medium, provided the original work is properly cited.
World Health Organization reported that depression is the fourth most disabling medical condition worldwide based on disability-adjusted life years. They predicted that depression will be the second most disabling condition worldwide by $2020 .{ }^{4} \mathrm{MDD}$ is a major economic burden to the healthcare system. In 1990, total annual cost of affective disorders in the United States was about $\$ 44$ billion. ${ }^{5}$ Therefore, preventing and treating MDD is a big issue.

Fortunately, treating patients with MDD using antidepressant medications is effective for controlling symptoms, restoring functional status, and preventing recurrent episodes. Antidepressants show an approximately $60 \%$ response rate in unipolar nonpsychotic depression, which is significantly superior to the $20-40 \%$ response rate of placebo. ${ }^{6}$ Relapse and recurrence of MDD can be reduced by maintaining antidepressant use. Most all double-blind, randomized studies of 
antidepressant therapy for depression show lower recurrence rates in antidepressant groups than those in placebo groups. ${ }^{7}$ Most depression treatment guidelines recommended maintenance treatment and continuation of antidepressant treatment after symptom remission. For example, the American Psychiatric Association Practice Guidelines for Treatment of Patients with Major Depressive Disorder recommend that patients whose mood has improved with antidepressant use during an acute phase should maintain treatment for 4-9 months. ${ }^{8}$ The Canadian Network for Mood and Anxiety Treatment Clinical guidelines for managing MDD also recommend that patients should maintain antidepressant use for at least 6-9 months after full symptom remission and that patients with some risk factors, such as recurrent episodes $(\geq 3)$, psychotic episodes, chronic episodes, significant comorbidities, or difficult-to-treat episodes, should be maintained on antidepressant medication for at least 2 years and some may require even lifetime use. ${ }^{9}$

Despite the importance of maintenance treatment for depression, many patients discontinue antidepressant medication earlier in the course of treatment. About $31 \%$ of patients have at least one 3 -day drug holiday during 9 weeks. ${ }^{10}$ About $28 \%$ of patients stop taking their antidepressant within 1 month, and $44 \%$ within 3 months. ${ }^{11}$ Such a high early discontinuation rate is a major obstacle for effective treatment of MDD. ${ }^{12,13}$ Moreover, the degree of non-compliance and time to all-cause medication discontinuation has been recognized as an important global index of medication effectiveness because reflects the judgment of patients and clinicians on the effectiveness, safety, and tolerability of medication. ${ }^{14}$ Therefore, time to medication discontinuation has been used as a primary outcome measure in some psychiatric studies. ${ }^{15,16}$

Several retrospective studies in Korea have investigated discontinuation of antidepressant medication and continuity of outpatient treatment after discharge of patients with depression. ${ }^{17,18}$ Two studies reported that treatment discontinuation rates were $43.5 \%$ at 6 weeks and $72.4 \%$ at 6 months. The type of antidepressant medication did not affect the risk of early treatment discontinuation. However, some limitations were mentioned, such as omission of commonly used antidepressants in Korea (e.g., escitalopram), a relatively small number of subjects, a short data collection period, and data collected from only one hospital.

Although new antidepressant medications are rapidly accepted by prescribing psychiatrists based of evidence from randomized trials, conventional randomized trials may no reveal the actual clinical influence of a medication, ${ }^{19}$ as no absolute inclusion/exclusion criteria or systematized randomization of patients occur in actual practice. ${ }^{20}$ In a way, observational data may be more representative of actual clinical practice ${ }^{19}$ and an- tidepressant discontinuation rates could differ between conventional randomized and observational studies.

The aim of the present study was to investigate differences in discontinuation time among antidepressant medications and the total antidepressant discontinuation rate in patients with depression over 6 months in a naturalistic treatment setting.

\section{METHODS}

We reviewed the medical records of 900 patients (150/hospital) who visited six hospitals (Pusan National University Hospital, Dong-A University Medical Center, Bongseng Memorial Hospital, Inje University Paik Hospital, Maryknoll Hospital, and Kosin University Gospel Hospital). Data were collected consecutively by each hospital until 150 subjects had been recruited by each hospital beginning on 28 February 2007. Written informed consent was obtained from all enrolled patients. This trial was approved by the institutional review board of each hospital.

The inclusion criteria were: 1) Patients who had a new depressive episode and who were diagnosed with MDD according to Diagnostic and Statistical Manual of Mental Disorders, Fourth Edition criteria. 2) Patients who were initially prescribed only one kind of antidepressant. 3) Patients who started taking an antidepressant before 1 March 2007. 4) Patients $\geq 18$ years old when the medication was prescribed.

A new episode included first onset, relapse, or a recurrence. It is difficult in clinical practice to discriminate between relapse and recurrence. ${ }^{6}$ Thus, we included both groups into a relapse (or re-treatment) group for convenience.

We surveyed information on age, sex, education, marital status, occupation, location of residence, age at onset, number of episodes, disease recurrence, and clinical severity at baseline. The antidepressants prescribed were surveyed at baseline and every 4 weeks during the 24 weeks. We defined discontinuation as no visits beyond 8 weeks since the last visit, switching to another antidepressant, or adding another antidepressant. The reasons for discontinuation were classified into six subgroups of no visits, no efficacy, side effects, patient or caregiver demand, unknown, and other.

According to these records, we determined discontinuation rates and mean times to discontinuation in the six antidepressants groups.

The chi-square test was used to examine early discontinuation rates of the antidepressants. Kaplan-Meyer survival curves and the log-rank test were used to determine mean times to discontinuation. A p-value $<0.05$ was considered significant. The calculations were carried out using SAS ver. 9.1 for Windows software (SAS Institute, Cary, NC, USA). 


\section{RESULTS}

Table 1 summarizes the demographic data and clinical characteristics of the 877 patients. We excluded antidepressants taken by $<50$ subjects for convenience. Finally, $739 \mathrm{pa}-$ tients and six antidepressants (fluoxetine, paroxetine, sertraline, escitalopram, mirtazapine, and venlafaxine) were analyzed. Another Korean study that analyzed the naturalistic prescribing pattern of antidepressants showed that these six antidepressants are used more frequently than others. ${ }^{21}$ The majority of our patients were female (73.5\%), married (65.2\%), urban living (80.0\%), and unemployed (72.3\%). The mean baseline Clinical Global Impressions Scale (CGI-S) score was $4.24( \pm 0.92)$, and $71.6 \%$ of patients were suffering their first depressive episode. Mean onset age was 48.5 years, and the mean number of episodes was 1.75 .
A comparison of discontinuation times is shown in Table 2. Mean and median overall discontinuation times were 13.8 and 12 weeks, respectively. The order of longer mean time to discontinuation was sertraline, escitalopram, venlafaxine, paroxetine, mirtazapine, and fluoxetine. Table 3 shows the pairwise comparison results for discontinuation time and the hazard ratios. Sertraline and escitalopram had longer discontinuation times than that of fluoxetine, and patients who used sertraline discontinued use significantly later than those taking mirtazapine.

Table 4 shows the antidepressant discontinuation rates after 24 weeks. No differences in discontinuation rates were observed among the antidepressants. About $73 \%$ of patients discontinued antidepressant treatment after 24 weeks.

Table 5 shows the reasons for discontinuation, and significant differences were detected between antidepressants in

Table 1. Demographic data and clinical characteristics of the subjects

\begin{tabular}{|c|c|c|c|c|c|c|c|c|}
\hline Category & $\begin{array}{c}\text { Total } \\
\mathrm{N}=739 \\
(\%)\end{array}$ & $\begin{array}{c}\text { Fluoxetine } \\
\qquad \begin{array}{c}\mathrm{N}=78 \\
(10.6)\end{array}\end{array}$ & $\begin{array}{c}\text { Paroxetine } \\
\mathrm{N}=188 \\
(25.4)\end{array}$ & $\begin{array}{c}\text { Sertraline } \\
\qquad \mathrm{N}=68 \\
(9.2)\end{array}$ & $\begin{array}{c}\text { Escitalopram } \\
\mathrm{N}=144 \\
(19.5)\end{array}$ & $\begin{array}{c}\text { Mirtazapine } \\
\mathrm{N}=161 \\
(21.8)\end{array}$ & $\begin{array}{c}\text { Venlafaxine } \\
\mathrm{N}=100 \\
(13.5)\end{array}$ & $\begin{array}{c}\chi^{2} \text { or } \\
\text { ANOVA }\end{array}$ \\
\hline \multicolumn{9}{|l|}{ Age (years) } \\
\hline Mean \pm SD & $53.3( \pm 15.9)$ & $41.8( \pm 17.8)$ & $52.0( \pm 14.6)$ & $58.0( \pm 15.9)$ & $55.0( \pm 15.6)$ & $57.8( \pm 14.8)$ & $51.7( \pm 14.1)$ & $\mathrm{F}=13.8^{\dagger}$ \\
\hline Female (\%) & $543(73.5 \%)$ & $58(74.4 \%)$ & $144(76.6 \%)$ & $53(77.9 \%)$ & $102(70.8 \%)$ & $114(70.8 \%)$ & $72(72.0 \%)$ & 3.1 \\
\hline \multicolumn{9}{|l|}{ Marital status (\%) } \\
\hline Married & $482(65.2 \%)$ & $42(53.8 \%)$ & $124(66.0 \%)$ & $50(73.5 \%)$ & $96(66.7 \%)$ & $105(65.2 \%)$ & $65(65.0 \%)$ & $58.2^{\dagger}$ \\
\hline Single & $96(13.0 \%)$ & $26(33.3 \%)$ & $27(14.4 \%)$ & $5(7.4 \%)$ & $14(9.7 \%)$ & $15(9.3 \%)$ & $9(9.0 \%)$ & \\
\hline Separated/divorced/widowed & $130(17.6 \%)$ & $9(11.5 \%)$ & $32(17.0 \%)$ & $11(16.2 \%)$ & $29(20.1 \%)$ & $28(17.4 \%)$ & $21(21.0 \%)$ & \\
\hline Do not know & $31(4.2 \%)$ & $1(1.3 \%)$ & $5(2.7 \%)$ & $2(2.9 \%)$ & $5(3.5 \%)$ & $13(8.1 \%)$ & $5(5.0 \%)$ & \\
\hline \multicolumn{9}{|l|}{ Education (years) } \\
\hline Mean \pm SD & $10.2( \pm 4.2)$ & $11.9( \pm 4.2)$ & $10.4( \pm 3.6)$ & $9.9( \pm 4.0)$ & $9.6( \pm 4.4)$ & $9.3( \pm 4.5)$ & $10.7( \pm 4.1)$ & $\mathrm{F}=4.6^{\dagger}$ \\
\hline \multicolumn{9}{|l|}{ Occupation (\%) } \\
\hline Unemployed & $534(72.3 \%)$ & $50(64.1 \%)$ & $135(71.8 \%)$ & $53(77.9 \%)$ & $110(76.4 \%)$ & $124(77.0 \%)$ & $62(62.0 \%)$ & $12.0^{*}$ \\
\hline Employed & $205(27.7 \%)$ & $28(35.7 \%)$ & $53(28.2 \%)$ & $15(22.1 \%)$ & $34(23.6 \%)$ & $37(23.0 \%)$ & $38(38.0 \%)$ & \\
\hline \multicolumn{9}{|l|}{ Location (\%) } \\
\hline Urban & $591(80.0 \%)$ & $63(80.8 \%)$ & $147(78.2 \%)$ & $54(79.4 \%)$ & 118 (81.9\%) & $131(81.4 \%)$ & $78(78.0 \%)$ & 13.0 \\
\hline Rural & $135(18.3 \%)$ & $11(14.1 \%)$ & 37 (19.7\%) & $11(16.2 \%)$ & $24(16.7 \%)$ & $30(18.6 \%)$ & $22(22.0 \%)$ & \\
\hline No record & $13(1.7 \%)$ & $4(5.1 \%)$ & $4(2.1 \%)$ & $3(4.4 \%)$ & $2(1.4 \%)$ & - & - & \\
\hline \multicolumn{9}{|l|}{ Age of onset (age) } \\
\hline Mean $\pm S D$ & $48.6( \pm 16.2)$ & $36.1( \pm 16.8)$ & $46.9( \pm 14.7)$ & $52.6( \pm 16.2)$ & $52.0( \pm 15.6)$ & $53.1( \pm 15.4)$ & $46.5( \pm 14.7)$ & $\mathrm{F}=16.2^{\dagger}$ \\
\hline \multicolumn{9}{|l|}{ Number of episode } \\
\hline Mean \pm SD & $1.8( \pm 1.4)$ & $1.8( \pm 1.0)$ & $1.9( \pm 1.4)$ & $1.9( \pm 1.3)$ & $1.6( \pm 1.1)$ & $1.5( \pm 0.9)$ & $2.0( \pm 2.3)$ & $\mathrm{F}=2.9^{*}$ \\
\hline \multicolumn{9}{|l|}{ MDD (\%) } \\
\hline 1st onset & $529(71.6 \%)$ & $44(56.4 \%)$ & $139(73.9 \%)$ & $49(72.1 \%)$ & 117 (81.3\%) & $110(68.3 \%)$ & $70(70.0 \%)$ & $22.4^{\dagger}$ \\
\hline Relapse & $191(25.8 \%)$ & $34(43.6 \%)$ & $45(23.9 \%)$ & $17(25.0 \%)$ & $21(14.6 \%)$ & $48(29.8 \%)$ & $26(26.0 \%)$ & \\
\hline \multicolumn{9}{|l|}{ CGI-S (baseline) } \\
\hline Mean \pm SD & $4.2( \pm 0.9)$ & $4.3( \pm 1.0)$ & $4.1( \pm 0.9)$ & $4.1( \pm 0.8)$ & $4.3( \pm 1.0)$ & $4.4( \pm 0.9)$ & $4.3( \pm 0.9)$ & $\mathrm{F}=3.4^{\dagger}$ \\
\hline
\end{tabular}

${ }^{*} \mathrm{p}<0.05,{ }^{\dagger} \mathrm{p}<0.001$. MDD: major depressive disorder, CGI-S: Clinical Global Impressions Scale 
reasons for discontinuation. "No visits" was the most common reason for discontinuing in all antidepressant groups.

\section{DISCUSSION}

We studied the mean time to discontinuation and the discontinuation rates of six commonly used antidepressants in patients with MDD, and the reasons for discontinuation in actual clinical practice. Some differences in time to discontinuation were detected among the antidepressants. Sertraline and escitalopram had longer more mean times to discontinuation than that of fluoxetine, and sertraline was taken significantly longer than mirtazapine. About three-fourths of patients discontinued antidepressant treatment after 6 months. "No visits" was the most common reason for discontinuing in all antidepressant groups.
Early medication discontinuation is very common in psychiatric trials. Treatment discontinuation should be evaluated carefully, because it can practically influence the credibility and clinical interpretation of clinical trial findings. ${ }^{22}$ Fewer actual effects of antidepressants are often observed in a naturalistic study than those observed in randomized controlled trials, which may be associated with decreased medication compliance. ${ }^{23}$ Treatment compliance is linked with treatment consequences because premature discontinuation of antidepressants increases the risk for suicide, and non-compliance by patients with a depressive disorder increases the chronic nature of the disease, leading to poor social outcomes. ${ }^{24}$

In the present study, the median overall treatment duration (12 weeks) was shorter than that recommended in the guidelines ( $>4$ months after symptom remission). Moreover, three-quarters of the patients discontinued antidepressant

Table 2. Overall comparisons of antidepressant medication discontinuation times

\begin{tabular}{lccccccc}
\hline & $\begin{array}{c}\text { Overall } \\
\mathrm{N}=739\end{array}$ & $\begin{array}{c}\text { Fluoxetine } \\
\mathrm{N}=78\end{array}$ & $\begin{array}{c}\text { Paroxetine } \\
\mathrm{N}=188\end{array}$ & $\begin{array}{c}\text { Sertraline } \\
\mathrm{N}=68\end{array}$ & $\begin{array}{c}\text { Escitalopram } \\
\mathrm{N}=144\end{array}$ & $\begin{array}{c}\text { Mirtazapine } \\
\mathrm{N}=161\end{array}$ & $\begin{array}{c}\text { Venlafaxine } \\
\mathrm{N}=100\end{array}$ \\
\hline $\begin{array}{l}\text { Kaplan-Meier time } \\
\text { to discontinuation }\end{array}$ & & & & & & & \\
Mean (week) & 13.8 & 12.3 & 13.7 & 15.6 & 14.6 & 13.1 & 12.0 \\
Median (week) & 12 & 8 & 12 & 16 & 12 & 12 & $7.4-16.6$ \\
$95 \% \mathrm{CI}$ & $10.5-13.5$ & $4.7-11.3$ & $9.6-14.4$ & $13.1-18.9$ & $8.4-15.6$ & $9.7-14.3$ &
\end{tabular}

Table 3. Pairwise comparison of antidepressant medication discontinuation times and hazard ratios

\begin{tabular}{|c|c|c|c|c|c|c|}
\hline & Fluoxetine & Paroxetine & Sertraline & Escitalopram & Mirtazapine & Venlafaxine \\
\hline \multicolumn{7}{|l|}{ Fluoxetine } \\
\hline Hazard ratio & & 0.84 & $0.66^{*}$ & $0.74^{*}$ & 0.91 & 0.76 \\
\hline $95 \% \mathrm{CI}$ & & $(0.62,1.13)$ & $(0.45,0.97)$ & $(0.54,1.01)$ & $(0.67,1.23)$ & $(0.54,1.07)$ \\
\hline \multicolumn{7}{|l|}{ Paroxetine } \\
\hline Hazard ratio & 1.19 & & 0.79 & 0.88 & 1.08 & 0.91 \\
\hline $95 \%$ CI & $(0.89,1.61)$ & & $(0.57,1.11)$ & $(0.68,1.14)$ & $(0.85,1.38)$ & $(0.68,1.21)$ \\
\hline \multicolumn{7}{|l|}{ Sertraline } \\
\hline Hazard ratio & $1.51^{*}$ & 1.26 & & 1.12 & $1.37^{*}$ & 1.15 \\
\hline $95 \% \mathrm{CI}$ & $(1.03,2.21)$ & $(0.9,1.77)$ & & $(0.79,1.59)$ & $(0.98,1.93)$ & $(0.79,1.67)$ \\
\hline \multicolumn{7}{|l|}{ Escitalopram } \\
\hline Hazard ratio & $1.35^{*}$ & 1.13 & 0.90 & & 1.23 & 1.03 \\
\hline $95 \%$ CI & $(0.99,1.85)$ & $(0.88,1.46)$ & $(0.63,1.27)$ & & $(0.94,1.60)$ & $(0.75,1.40)$ \\
\hline \multicolumn{7}{|l|}{ Mirtazapine } \\
\hline Hazard ratio & 1.10 & 0.92 & $0.73^{*}$ & 0.82 & & 0.84 \\
\hline $95 \% \mathrm{CI}$ & $(0.81,1.49)$ & $(0.72,1.17)$ & $(0.52,1.03)$ & $(0.63,1.06)$ & & $(0.62,1.12)$ \\
\hline \multicolumn{7}{|l|}{ Venlafaxine } \\
\hline Hazard ratio & 1.32 & 1.10 & 0.87 & 0.97 & 1.20 & \\
\hline $95 \%$ CI & $(0.94,1.86)$ & $(0.83,1.47)$ & $(0.6,1.27)$ & $(0.72,1.33)$ & $\left(\begin{array}{lll}0.89 & 1.61)\end{array}\right.$ & \\
\hline
\end{tabular}

${ }^{*} \mathrm{p}<0.05$ by log-rank (Mantel-Cox) test 
maintenance therapy after 24 weeks, and about $79 \%$ of the patients who stopped taking their medication did not return to follow-up visits. Only $17.4 \%$ of Taiwanese patients with depression continued overall antidepressant treatment for 180 days, ${ }^{25}$ and $44.3 \%$ of Japanese patients with depression continued antidepressant treatment for 6 months. Among patients who discontinued their initial antidepressant, 63.1\% did so without consulting their physician. ${ }^{26}$ A systematic review on preventing relapse by administering antidepressants reported that continuing antidepressant treatment with reduce the odds of relapse by $70 \%$ compared with discontinuing treatment. ${ }^{27}$ These results suggest that more effort is needed to improve the doctor-patient relationship and that public education about depression is needed for patients to achieve their treatment goals.

We found that patients who were taking sertraline or escitalopram tended to continue the medications longer, although the differences in discontinuation rates between antidepressants were not significant at 24 weeks. This result is similar to a recent multi-treatment meta-analysis for 12 new-generation antidepressants. Cipriani et al. reported that escitalopram and sertraline showed the best acceptability profile, leading to significantly fewer patients discontinuing their use than that of duloxetine, fluvoxamine, paroxetine, reboxetine, and ven-

Table 4. Discontinuation rates of antidepressants after 24 weeks of treatment

\begin{tabular}{lr}
\hline & 24 week \\
\hline Fluoxetine $\mathrm{N}=78(\%)$ & $63(80.8)$ \\
Paroxetine $\mathrm{N}=188(\%)$ & $139(73.9)$ \\
Sertraline $\mathrm{N}=68(\%)$ & $45(66.2)$ \\
Escitalopram $\mathrm{N}=144(\%)$ & $100(69.4)$ \\
Mirtazapine $\mathrm{N}=161(\%)$ & $125(77.6)$ \\
Venlafaxine $\mathrm{N}=100(\%)$ & $68(68.0)$ \\
Over all $\mathrm{N}=739(\%)$ & $540(73.1)$ \\
\hline
\end{tabular}

$\chi^{2}=8.041, \mathrm{p}=0.154$ by chi-square test lafaxine. ${ }^{28}$ Similarly, Mullins et al. reported that patients with depression, post-traumatic stress disorder, or a social anxiety disorder who were treated with paroxetine had lower persistence than those treated with sertraline and citalopram. ${ }^{29}$ Poluzzi et al. also reported that patients taking escitalopram and sertraline (including duloxetine) showed better adherence than those taking with paroxetine.$^{30}$ Esposito et al. also reported that patients taking escitalopram were more likely to continue and less likely to switch or augment their medication after 2 and 6 months of treatment compared with those taking fluoxetine, paroxetine, and citalopram group. ${ }^{31}$ Sawada et al. showed that sertraline use is associated with a higher persistence rate after 6 months of treatment compared to that of paroxetine and fluvoxamine. ${ }^{26}$

However, Gartlehner et al. reported that patients taking a selective serotonin reuptake inhibitor (SSRI) tended to have a similar or lower rate of discontinuation due to adverse effects than that of patients taking other antidepressants (mirtazapine, venlafaxine, and bupropion) but the difference was not significant. ${ }^{32}$ In addition, Lee et al. showed that the maintenance rates of patients taking mirtazapine, citalopram, fluoxetine, paroxetine, sertraline, or venlafaxine were not significantly different after 6 weeks of treatment. ${ }^{18}$

Generally, insufficient efficacy and frequent side effects are associated with a lower persistence rate in patients taking antidepressants. ${ }^{26}$ Therefore, the well-known efficacy and good tolerability of escitalopram ${ }^{33}$ and the better side-effect profile of sertraline may have contributed to the results of the present study. ${ }^{26}$ Some studies have reported that efficacy of escitalopram is superior to that of placebo and equal or superior to other SSRIs and serotonin-norepinephrine reuptake inhibitors. In addition, escitalopram shows favorable tolerability, and adverse effects are generally not severe or uncontrolled. ${ }^{33}$ Sertraline has a better side-effect profile. ${ }^{34}$

Our results should be interpreted cautiously and additional analysis may be needed because many variable factors in-

Table 5. Reasons for discontinuing antidepressant treatment

\begin{tabular}{|c|c|c|c|c|c|c|c|c|}
\hline Category & $\begin{array}{c}\text { Total } \\
\mathrm{N}=540(\%)\end{array}$ & $\begin{array}{c}\text { Fluoxetine } \\
\mathrm{N}=63(11.7)\end{array}$ & $\begin{array}{c}\text { Paroxetine } \\
\mathrm{N}=139(25.7)\end{array}$ & $\begin{array}{c}\text { Sertraline } \\
\mathrm{N}=45(8.3)\end{array}$ & $\begin{array}{l}\text { Escitalopram } \\
\mathrm{N}=100(18.5)\end{array}$ & $\begin{array}{c}\text { Mirtazapine } \\
\mathrm{N}=125(23.1)\end{array}$ & $\begin{array}{l}\text { Venlafaxine } \\
\mathrm{N}=68(12.6)\end{array}$ & $\chi^{2}$ \\
\hline \multicolumn{9}{|c|}{ Reasons for discontinuation } \\
\hline Not visiting & $429(79.4)$ & $47(74.6)$ & $98(70.5)$ & $42(93.3)$ & $83(86.0)$ & $102(81.6)$ & $54(79.4)$ & $50.26^{*}$ \\
\hline \multicolumn{9}{|l|}{ Switching or adding } \\
\hline Lack of efficacy & $56(10.4)$ & $10(15.9)$ & $20(14.4)$ & $1(2.2)$ & $7(7.0)$ & $10(8.0)$ & $8(11.8)$ & \\
\hline Side effect & $31(5.7)$ & $3(4.8)$ & $6(4.3)$ & - & $4(4.0)$ & $12(9.6)$ & $6(8.8)$ & \\
\hline Patient's request & $7(1.3)$ & - & $7(5.0)$ & - & - & - & - & \\
\hline Unknown & $16(3.0)$ & $3(4.8)$ & $7(5.0)$ & $2(4.4)$ & $3(3.0)$ & $1(0.8)$ & - & \\
\hline Other & $1(0.2)$ & - & $1(0.7)$ & 0 & - & - & - & \\
\hline
\end{tabular}

*p<0.05 by $\chi^{2}$ test 
fluence maintenance and discontinuation of antidepressants prescribed for the first time. Moreover, switching or adding medications and patient dropout occur for many reasons. Some factors related with antidepressant discontinuation rate have been proposed previously. The novelty of an antidepressant and the use experience of the physician may influence titration and target dose. Cost of the medication and demographic factors, such as patient age and sex, severity of depression, number of episodes, and experience with previous antidepressant therapy, may also be important factors, although their influence is inconsistent. . $^{18,26,29,35}$ Moreover, although we investigated the reasons for discontinuing antidepressant medication and we found significant differences between some of the reasons, "no visits" was clearly the most frequent reason given. Therefore, reasons for discontinuation may not be clinically significant. Additional research about patients who do not return for visits, useful methods to encourage treatment continuation and consideration of clinically influential factors is needed.

The limitations of our study should be mentioned. First, this study was based on a medical record review; thus, recall bias may have occurred and data may have been omitted. Second, we did not analyze factors other than the kind of antidepressant that could influence time to discontinuation. Third, we used the CGI-S to determine depression severity. Therefore, we could not assess severity of changes in depressive symptoms during treatment. Fourth, we did not randomize the antidepressants when they were first prescribed, which may have influenced the discontinuation rates among antidepressants. Nevertheless, we included most of the presently available antidepressants used commonly in clinical practice and compared mean discontinuation times and rates in an actual clinical situation.

In conclusion, sertraline and escitalopram tended to have longer mean times to discontinuation, although no difference in discontinuation rate was detected between antidepressants after 24 weeks. Because three-quarter of the patients discontinued antidepressant maintenance therapy, efforts to enhance treatment continuity are needed.

\section{Acknowledgments}

None of the authors has a conflict of interest in this study or during preparation of the manuscript. This study was funded by H. Lundbeck A/S. The funder had no role in study design or collection, analysis, or interpretation of the data, writing the report, or in the decision to submit the study for publication.

\section{REFERENCES}

1. Kessler RC, Berglund P, Demler O, Jin R, Merikangas KR, Walters EE. Lifetime prevalence and age-of-onset distributions of DSM-IV disorders in the National Comorbidity Survey Replication. Arch Gen Psychiatry 2005;62:593-602.
2. Kessler RC, Berglund P, Demler O, Jin R, Koretz D, Merikangas KR, et al. The epidemiology of major depressive disorder: results from the National Comorbidity Survey Replication (NCS-R). JAMA 2003;289: 3095-3105.

3. Wells KB, Stewart A, Hays RD, Burnam MA, Rogers W, Daniels M, et al. The functioning and well-being of depressed patients. Results from the Medical Outcomes Study. JAMA 1989;262:914-919.

4. Murray CJ, Lopez AD. Evidence-based health policy--lessons from the Global Burden of Disease Study. Science 1996;274:740-743.

5. Greenberg PE, Stiglin LE, Finkelstein SN, Berndt ER. The economic burden of depression in 1990. J Clin Psychiatry 1993;54:405-418.

6. Hales RE, Yudofsky SC. The American Psychiatric Publishing Textbook of Clinical Psychiatry. Washington, DC: American Psychiatric Pub; 2003.

7. Solomon DA, Bauer MS. Continuation and maintenance pharmacotherapy for unipolar and bipolar mood disorders. Psychiatr Clin North Am 1993;16:515-540.

8. American Psychiatric Association. Practice Guideline for Major Depressive Disorder in Adults. Washington, DC: The Association; 1993.

9. Lam RW, Kennedy SH, Grigoriadis S, McIntyre RS, Milev R, Ramasubbu R, et al. Canadian Network for Mood and Anxiety Treatments (CANMAT) clinical guidelines for the management of major depressive disorder in adults. III. Pharmacotherapy. J Affect Disord 2009;117 (Suppl 1):S26-S43.

10. Demyttenaere K, Mesters P, Boulanger B, Dewe W, Delsemme MH, Gregoire J, et al. Adherence to treatment regimen in depressed patients treated with amitriptyline or fluoxetine. J Affect Disord 2001;65:243252.

11. Lin EH, Von Korff M, Katon W, Bush T, Simon GE, Walker E, et al. The role of the primary care physician in patients' adherence to antidepressant therapy. Med Care 1995;33:67-74.

12. Katon W, von Korff M, Lin E, Bush T, Ormel J. Adequacy and duration of antidepressant treatment in primary care. Med Care 1992;30:67-76.

13. Demyttenaere K, Van Ganse E, Gregoire J, Gaens E, Mesters P. Compliance in depressed patients treated with fluoxetine or amitriptyline. Belgian Compliance Study Group. Int Clin Psychopharmacol 1998;13:11-17.

14. Ascher-Svanum H, Zhu B, Faries D, Landbloom R, Swartz M, Swanson $\mathrm{J}$. Time to discontinuation of atypical versus typical antipsychotics in the naturalistic treatment of schizophrenia. BMC Psychiatry 2006;6:8.

15. Kroken RA, Kjelby E, Wentzel-Larsen T, Mellesdal LS, Jorgensen HA, Johnsen E. Time to discontinuation of antipsychotic drugs in a schizophrenia cohort: influence of current treatment strategies. Ther Adv Psychopharmacol 2014;4:228-239.

16. Kreyenbuhl J, Slade EP, Medoff DR, Brown CH, Ehrenreich B, Afful J, et al. Time to discontinuation of first- and second-generation antipsychotic medications in the treatment of schizophrenia. Schizophr Res 2011;131:127-132.

17. Lee YM, Lee KU. Time to discontinuation among the three secondgeneration antidepressants in a naturalistic outpatient setting of depression. Psychiatry Clin Neurosci 2011;65:630-637.

18. Lee KU, Kim W, Min KJ, Shin YC, Chung SK, Bahk WM. The rate and risk factors of early discontinuation of antidepressant treatment in patients with major depressive disorder. Korean J Psychopharmacol 2006; 17:550-556.

19. Simon G, Wagner E, Vonkorff M. Cost-effectiveness comparisons using "real world" randomized trials: the case of new antidepressant drugs. J Clin Epidemiol 1995;48:363-373.

20. Ham BJ, Han CH. Optimising antidepressant use in clinical practice: considering external factors. J Korean Neuropsychiatr Assoc 2008;47: 22-27.

21. Bae KY, Kim SW, Kim JM, Shin IS, Yoon JS, Jung SW, et al. Antidepressant prescribing patterns in Korea: results from the clinical research center for depression study. Psychiatry Investig 2011;8:234-244.

22. Spineli LM, Leucht S, Cipriani A, Higgins JP, Salanti G. The impact of trial characteristics on premature discontinuation of antipsychotics in 
schizophrenia. Eur Neuropsychopharmacol 2013;23:1010-1016.

23. Hansen HV, Kessing LV. Adherence to antidepressant treatment. Expert Rev Neurother 2007;7:57-62.

24. Lee MS, Lee HY, Kang SG, Yang J, Ahn H, Rhee M, et al. Variables influencing antidepressant medication adherence for treating outpatients with depressive disorders. J Affect Disord 2010;123:216-221.

25. Wu CS, Shau WY, Chan HY, Lai MS. Persistence of antidepressant treatment for depressive disorder in Taiwan. Gen Hosp Psychiatry 2013;35: 279-285.

26. Sawada N, Uchida H, Suzuki T, Watanabe K, Kikuchi T, Handa T, et al. Persistence and compliance to antidepressant treatment in patients with depression: a chart review. BMC Psychiatry 2009;9:38.

27. Geddes JR, Carney SM, Davies C, Furukawa TA, Kupfer DJ, Frank E, et al. Relapse prevention with antidepressant drug treatment in depressive disorders: a systematic review. Lancet 2003;361:653-661.

28. Cipriani A, Furukawa TA, Salanti G, Geddes JR, Higgins JP, Churchill $\mathrm{R}$, et al. Comparative efficacy and acceptability of 12 new-generation antidepressants: a multiple-treatments meta-analysis. Lancet 2009;373: 746-758.

29. Mullins CD, Shaya FT, Meng F, Wang J, Harrison D. Persistence, switching, and discontinuation rates among patients receiving sertraline, paroxetine, and citalopram. Pharmacotherapy 2005;25:660-667.

30. Poluzzi E, Piccinni C, Sangiorgi E, Clo M, Tarricone I, Menchetti M, et al. Trend in SSRI-SNRI antidepressants prescription over a 6-year period and predictors of poor adherence. Eur J Clin Pharmacol 2013;69:20952101.

31. Esposito D, Wahl P, Daniel G, Stoto MA, Erder MH, Croghan TW. Results of a retrospective claims database analysis of differences in antidepressant treatment persistence associated with escitalopram and other selective serotonin reuptake inhibitors in the United States. Clin Ther 2009;31:644-656.

32. Gartlehner G, Hansen RA, Carey TS, Lohr KN, Gaynes BN, Randolph LC. Discontinuation rates for selective serotonin reuptake inhibitors and other second-generation antidepressants in outpatients with major depressive disorder: a systematic review and meta-analysis. Int Clin Psychopharmacol 2005;20:59-69.

33. Kirino E. Escitalopram for the management of major depressive disorder: a review of its efficacy, safety, and patient acceptability. Patient Prefer Adherence 2012;6:853-861.

34. Burra TA, Chen E, McIntyre RS, Grace SL, Blackmore ER, Stewart DE. Predictors of self-reported antidepressant adherence. Behav Med 2007; 32:127-134.

35. Vanelli M, Coca-Perraillon M. Role of patient experience in antidepressant adherence: a retrospective data analysis. Clin Ther 2008;30: 1737-1745. 